\title{
EL SIGNIFICADO PSICOLÓGICO DE LAS CINCO FASES DEL DUELO PROPUESTAS POR KÜBLER-ROSS MEDIANTE LAS REDES SEMÁNTICAS NATURALES
}

\section{THE PSYCHOLOGICAL SIGNIFICANCE OF THE FIVE STAGES OF GRIEF PROPOSED BY KÜBLER-ROSS THROUGH NATURAL SEMANTIC NETWORKS}

\author{
Melina Miaja Ávila y José Moral de la Rubia \\ Facultad de Psicología, Universidad Autónoma de Nuevo León Monterrey, Mexico
}

Resumen

Los objetivos del estudio fueron: 1) identificar el significado psicológico de las cinco fases del proceso del duelo propuestas por Kübler-Ross, y 2) diseñar una escala para medir las cinco fases del duelo ante la pérdida de la salud desde los resultados obtenidos. Se aplicó un test de asociación libre de palabras con la técnica de redes semánticas naturales a una muestra no probabilística intencional de 18 pacientes oncológicos y 12 cuidadores primarios. Se encontraron que las asociaciones de palabras eran congruentes con la expectativa teórica. A partir de estas palabras y algunas consideraciones teóricas se redactaron 67 ítems. Al ser sometidos al juicio de 9 expertos, un ítem fue eliminado y 19 corregidos. Se discuten los resultados para aclarar el contenido de las fases. Finalmente se presenta la Escala de la Fases del Duelo de 66 ítems tipo Likert para su posterior estudio psicométrico.

Palabras clave: Significado, duelo, negación, ira, negociación, depresión, aceptación.

\section{Abstract}

The aims of the study were: 1 ) to identify the psychological significance of the five stages of the grief process proposed by Kübler-Ross, and 2) to design a scale to measure the five stages of grief at the health loss from the obtained results. A test of free association of words from the natural semantic network technique was applied to a non-probabilistic intentional sample of 18 cancer patients and 12 primary caregivers. It was found that the word associations were consistent with the theoretical expectation. From these words and some theoretical considerations, 67 items were written. The items were subjected to the judgment of 9 experts. One item was removed and 19 were corrected. The results are discussed to clarify the content of the phases. Finally the 66-item Likert type Grief Stages Scale was presented for further psychometric study.

Keywords: Meaning, grief, denial, anger, bargaining, depression, acceptance. 


\section{INTRODUCCIÓN}

Las teorías de las etapas del proceso del duelo postulan que los enfermos terminales o deudos pasan a través de una secuencia de reacciones emocionales, que les permiten protegerse de la amenaza de las pérdidas inminentes ${ }^{(1,2)}$. Kübler-Ross ${ }^{(2)}$ señaló que las personas que se encontraban próximas a la muerte (enfermos terminales) transitaban por cinco fases durante el duelo: negación, ira, pacto/negociación, depresión y aceptación. La autora observó que estas fases duraban diferentes periodos de tiempo; y se sucedían unas a otras o que en ocasiones se solapaban.

Kübler-Ross ${ }^{(2)}$ definió negación como la imposibilidad de aceptar y reconocer como un hecho real que se padezca la enfermedad, por lo que el diagnóstico recibido se atribuye a errores médicos o algún tipo de equivocación. La ira es definida como una reacción emocional de rabia, envidia, resentimiento y hostilidad por haber perdido la salud y es dirigida hacia todo el entorno que se percibe como sano o responsable de la enfermedad, ya sea personal sanitario, familiares, amistades, incluso hacia Dios. También incluye la ira u hostilidad dirigida hacia sí mismo al culparse de haberse provocado la enfermedad, pudiéndose incurrir en conductas de riesgo autodestructivas. El pacto/ negociación es una forma de afrontar la culpa y se entabla, de forma imaginaria o real, con aquéllos hacia las cuales dirigió la ira. Ahora no se perciben como culpables, sino comprometidos con la recuperación del paciente, por lo que éste les hace promesas para alcanzar metas terapéuticas, de supervivencia o desarrollo personal. Se abandona cualquier conducta autodestructiva y empieza a comprometerse con la recuperación. La depresión son sentimientos de un profundo vacío y dolor ante la penosa situación que el paciente vive, adoptándose una actitud de claudi- cación ante la enfermedad. En esta fase puede abandonar el tratamiento y dejar de ir a las citas médicas. La aceptación se define como el reconocimiento de la enfermedad y situación de dolor y limitaciones que conlleva, sin buscar culpables, ni adoptar una posición de derrota, sino asumir una actitud responsable de lucha y supervivencia. A esta fase se alcanza tras realizar un balance de la pérdida y dar nuevos significados a la situación que se vive. Kübler-Ross ${ }^{(2)}$ señalaba que la fase de aceptación no debía confundirse con una resignación ante la enfermedad o alcanzar un estado de felicidad.

Un problema para el estudio de las cinco fases del proceso del duelo es la confusión que existe alrededor de los constructos. Moyer y Levine ${ }^{(3)}$ señalaron que existe una falta de consenso sobre si la negación es un signo de perturbación psicológica o una respuesta normal ante una enfermedad que amenaza la vida. El consenso se inclina hacia su consideración como una respuesta normal, lo que es afín a la propuesta original de Kübler-Ross ${ }^{(2)}$. Para Moyer y Levine ${ }^{(3)}$ la negación se refiere a la necesidad de distanciarse, evitar y suprimir emociones. En una revisión de 18 artículos, Wheeler y Louann ${ }^{(4)}$ encontraron que los conceptos más utilizados para definir la negación son evitación, represión y esperanza poco realista, los cuales no implican psicopatología. Asimismo, Rabinowitz y Peirson ${ }^{(5)}$ señalaron que la negación es el proceso por el cual la persona se defiende de pensamientos, sentimientos o de información dolorosa o amenazante, y puede manifestarse tanto en personas sanas como en personas con alguna enfermedad, y/o en los familiares del paciente.

En relación con el concepto de depresión, González y Valdez ${ }^{(6)}$ encontraron que su definición difiere entre médicos y psicólogos. Por un lado, los médicos privilegian los aspectos biológicos y los psicólogos los aspectos afectivos, cognitivos y sociales. 
En relación al constructo de aceptación, algunos autores utilizan el término resignación como una estrategia de afrontamiento emocional para referirse a la aceptación de la situación como algo inamovible ${ }^{(7)}$. Otros investigadores señalan que es más realista hablar de adaptación a la enfermedad $^{(8)}$ debido a que no solo el ser diagnosticado precipita una crisis, sino que cada fase nueva de la enfermedad perturba la homeóstasis, forzando al paciente y a la familia a adaptarse a nuevas tareas. Por otra parte, hay quienes equiparan la aceptación a estoicismo o resignación, como se observa en los trabajos de Rodríguez, Terol, López y Pastor ${ }^{(7)}$ y Sánchez y Dos Santos ${ }^{(9)}$.

La mayoría de las investigaciones estudian el proceso del duelo en pacientes terminales ${ }^{(10-12)}$ o en deudos por la muerte de un ser querido ${ }^{(13-17)}$. Como consecuencia de esto los instrumentos de medición están enfocados a este tipo de pérdida, como el Inventario de Experiencias en Duelo (IED) ${ }^{(18)}$ y el Inventario Texas Revisado de Duelo $(\text { ITRD })^{(19)}$.

Newman et al. ${ }^{(20)}$ y Worden $^{(21)}$ señalan que las fases del proceso del duelo pueden ser experimentadas no sólo en situaciones de enfermedades terminales, sino ante cualquier tipo de pérdida significativa. Por lo tanto, consideramos de gran importancia desarrollar un instrumento que nos permita evaluar las fases del proceso del duelo ante la pérdida de la salud y de los múltiples cambios en la vida diaria que conlleva el padecer una enfermedad crónica, como el cáncer.

Para la creación de un nuevo instrumento que evalúe las fases de duelo ante situaciones de pérdida de la salud, lo más adecuado sería adoptar un enfoque teórico desde la formulación original de Kübler-Ross ${ }^{(2)}$ y así garantizar la validez de contenido y poder contrastar la teoría. No obstante, también se podría complementar con un enfoque empírico sensible a la cultura. Precisamente Valdez ${ }^{(22,23)}$ señala que cada vez es mayor la necesidad de construir instrumentos de medición con bases etnopsicológicas, es decir, tomando en cuenta la participación de las personas que viven y comparten una cultura en particular para que éste alcance mayor sensibilidad (capacidad de detectar casos) y especificidad (capacidad de rechazar no casos). A tal fin puede ser útil la técnica de redes semánticas naturales, la cual permitiría desentrañar el significado psicológico que los pacientes tienen sobre las fases del duelo.

Desde la teoría de las redes semánticas naturales, el significado psicológico se refiere a una organización cognoscitiva en forma de red asociativa en torno al núcleo de una representación-palabra. El significado está compuesto de información muy diversa desde referencia a objetos concretos, eventos, afectos y conocimientos a relaciones lógicas y temporales. Todos estos elementos crean un código subjetivo de reacción ${ }^{(24,25)}$. De este modo, la red asociativa permite tener una idea clara sobre la información en la memoria, y da acceso al significado que se tiene de un concepto en específico ${ }^{(23)}$. Así, el significado psicológico refleja la imagen del universo y la cultura subjetiva que tiene el individuo, la cual juega un papel importante en la producción de la conducta.

Este estudio tiene como objetivos conocer el significado psicológico que tienen los pacientes con cáncer y los cuidadores primarios sobre las cinco fases del duelo ante la pérdida de la salud. Con esta información, considerando las definiciones dadas por Kübler-Ross ${ }^{(2)}$ se pretende redactar los reactivos de una escala con un formato tipo Likert, y posteriormente someter los mismos al juicio de un grupo de expertos en oncología, tanatología o cuidados paliativos. Con base en las sugerencias se fijará el formato inicial de la escala. En una investigación posterior se realizará la selección final de los ítems con base en sus 
propiedades de consistencia, estabilidad y validez. Por lo tanto, la contribución de este estudio, aparte de clarificar los conceptos de las fases del duelo, es proponer una escala que evalúe estas fases con un origen mixto empírico-teórico.

\section{MÉTODO}

\section{Participantes}

La muestra no probabilística intencional de participantes voluntarios estuvo conformada por 18 (60\%) pacientes oncológicos y 12 (40\%) cuidadores primarios, siendo estadísticamente equivalente la frecuencia de pacientes y parientes por la prueba binomial $(p=0,36)$. El criterio de inclusión para ambas muestras fue: saber leer y escribir. Como criterios de exclusión se fijaron: déficit cognitivo que impidiese comprender las instrucciones, fatiga excesiva que dificultase la atención o negativa a participar.

\section{Instrumentos}

Se construyó un instrumento formado por siete hojas tamaño media cuartilla (esquela). La primera hoja contenía las instrucciones y un ejemplo. La última hoja contenía los datos socio-demográficos y clínicos (para los pacientes con cáncer). Las hojas intermedias contenían, en su parte superior, las cinco palabrasestímulo contextualizadas ante la situación de enfermedad: 1) para mí negar la enfermedad es, 2) para mí la ira ante la enfermedad es, 3) para mí negociar con la enfermedad es, 4) para mí la depresión ante la enfermedad es y 5) para mí aceptar la enfermedad es.

La aplicación del instrumento de autoinforme fue grupal. El tiempo promedio empleado para contestarlo fue de aproximadamente 15 minutos.

\section{Procedimiento}

Para este estudio se utilizó un muestreo no probabilístico de tipo intencional, extrayendo la muestra de un albergue de la Cruz Rosa, que es una asociación de beneficencia privada.

Antes de comenzar con el estudio se proporcionó el protocolo de investigación a la institución anfitriona con la finalidad de obtener su aprobación y poder así llevar a cabo el proyecto de investigación. Para la administración del instrumento se les pidió a los pacientes y cuidadores primarios firmar la carta de consentimiento informado. En los menores de edad, la carta de consentimiento informado fue firmada por el cuidador primario (mayor de edad) y por el mismo paciente. De este modo se atendió a las normas éticas para la investigación de la Sociedad Mexicana de Psicología ${ }^{(26)}$.

Los participantes que aceptaron formar parte del estudio respondieron por escrito al instrumento en presencia del entrevistador. Para contestar el instrumento se les pidió a los participantes que realizaran dos tareas: 1) escribir al menos cinco palabras que relacionen de manera significativa con el enunciado (palabra-estímulo); y 2) ordenar cada una de las palabras que escribieron (definidoras) de acuerdo a su relación de importancia o cercanía al enunciado, es decir, que escribieran el número 1 junto a la palabra que define mejor la palabra-estímulo o la que sea más cercana, el número dos a la segunda palabra más importante y así sucesivamente hasta terminar la lista.

Desde la red semántica, con los descriptores obtenidos, se hizo una primera redacción de los ítems de la Escala de Fases del Duelo (EFD). Estos fueron sometidos a evaluación de su pertinencia teórica y comprensibilidad, empleándose un grupo de 9 expertos en tanatología, psicooncología y cuidados paliativos. La participación de los expertos fue por invitación 
y no remunerada. Se les proporcionó un formato de valoración para cada ítem con 3 puntos: 1 = no es adecuado, 2 = sí, pero con cambios, y 3 = sí, es adecuado. Se dejaba un espacio en blanco para que señalasen qué cambios consideraban pertinentes en caso de marcar la opción 2.

\section{Análisis de los datos}

El análisis de la red semántica se realizó en la muestra conjunta, ya que la escala pretende evaluar las fases del duelo por la pérdida de la salud tanto en pacientes (salud propia) como en parientes (del familiar). No obstante, la descripción sociodemográfica de la muestra se complementó con la comparación entre el grupo de pacientes y parientes para tener una idea más clara de su composición. La comparación de frecuencias entre ambos grupos se realizó por la prueba chi-cuadrado, de promedio en el nivel de escolaridad por la $U$ de Mann-Whitney y de medias de edad por la prueba $t$ de Student. La equivalencia de la frecuencia de sexos en cada grupo se contrastó por la prueba binomial.

La red semántica de cada palabra-estimulo se describió por medio de cuatro elementos: el valor J (tamaño de la red), valor $M$ (peso semántico de cada definidora), conjunto SAM (núcleo central de la red semántica) y valor FMG (distancia semántica de las definidoras dentro del conjunto SAM). El valor J se obtiene contando el número total de palabras definidoras. El valor $\mathrm{M}$ consiste en la suma de las frecuencias de orden de importancia ponderadas por su peso semántico. El conjunto SAM son las quince palabras con mayor valor M o peso semántico (González y Valdez, 2005). El valor FMG se obtiene al aplicar una regla de tres. Se estima el valor FMG que corresponde al peso semántico de cada palabra definidora tomando como referencia el valor semántico correspondiente a la primera definidora cuyo valor
FMG asignado es 100. Por ejemplo, en la red semántica de depresión, la palabra con mayor peso semántico fue triste (valor $\mathrm{M}=$ 71), así el valor FMG que se le asignó fue 100. La palabra llorar tuvo un valor M de 59. Al aplicar la regla de tres su valor FMG sería: $(59 \times 100) / 71=83.10$.

Desde la valoración de los 9 expertos, los ítems se aceptaron cuando al menos 7 expertos lo señalaron como "sí es adecuado" $(77,8 \%)$, se rechazaron cuando 6 expertos lo señalaron como "no es adecuado" $(66,7 \%)$. En los demás casos se procedió a su modificación, retomando las sugerencias. En caso de juzgarlas inapropiadas o erróneas se dejó el ítem sin cambios.

\section{RESULTADOS}

\section{Descripción de la muestra}

En la muestra conjunta, 26 de los participantes $(87 \%)$ fueron mujeres y $4(13 \%)$ hombres, siendo la frecuencia de mujeres significativamente mayor que la de los hombres (prueba binomial: $p=0,15$ ). La media de edad fue de 45,20 años (DT = 14,44), variando de 17 a 69 años. En relación a los estudios, 9 (30\%) indicó tener estudios de primaria, 5 (17\%) secundaria, 7 (23\%) media superior y 9 (30\%) estudios profesionales. En relación al estado civil, 5 (17\%) dijeron ser solteros, 1 (3\%) vivir en unión libre, 21 (70\%) estar casados, 2 (7\%) viudos y 1 (3\%) separado.

El porcentaje entre los sexos fue estadísticamente equivalente entre pacientes y parientes $\left(\chi^{2}[1, N=30]=0,97, p=0,32\right)$, con mayor frecuencia de mujeres en ambas muestras. La edad de los pacientes fue significativamente mayor que la de los parientes $(\mathrm{t}[28]=2,41, \mathrm{p}=0,02)$ con una diferencia media de 12 años (95\% IC: 1,79, 22,21). Entre los parientes, 7 (58,1\%) señalaron ser hijos, 3 (25\%) hermanas, 1 (8,3\%) cuñada y $1(8,3 \%)$ padre. El nivel de escolaridad 
fue estadísticamente equivalente entre ambas muestras $(U=85, Z=-1,01, p=0,31)$ con un promedio correspondiente a media superior. También la distribución de estado civil fue estadísticamente equivalente $(\chi 2$ [4, $\mathrm{N}=30]=6,03, \mathrm{p}=0,17$ exacta), con dominio de los casados.

En la muestra clínica, 17 pacientes $(94,4 \%)$ fueron mujeres y $1(5,6 \%)$ hombre, habiendo diferencia significativa en la frecuencia de sexos (prueba binomial: $p<$ $0,01)$. La media de edad fue de 50 años $(\mathrm{DT}=13,92)$. En relación a los estudios, $8(44.4 \%)$ pacientes indicaron tener estudios de primaria, $2(11,1 \%)$ secundaria, 2 $(11,1 \%)$ media superior y $6(33,3 \%)$ estudios profesionales. En relación al estado civil, 1 (5,6\%) dijo ser soltero, 1 (5,6\%) vivir en unión libre, $13(72,2 \%)$ estar casados, $2(11,1 \%)$ viudos y $1(5,6 \%)$ separado. De los 18 pacientes, 10 (55,6\%) reportaron padecer cáncer de mama, 4 (22,2\%) tumores que afectan al sistema nervioso central, $3(16,7 \%)$ al aparato reproductor y 1 (5,5\%) cáncer abdominal. La media del tiempo transcurrido desde el diagnóstico fue de 1,47 años (DT = 1,69).

En la muestra de cuidadores primarios, $9(75 \%)$ fueron mujeres y $3(25 \%)$ hombres, siendo estadísticamente equivalente la frecuencia de ambos sexos (prueba binomial: $p=0,15)$. La media de edad fue de 38 años $(D T=12,47)$. En relación a los estudios, 1 (8,3\%) indicó tener estudios de primaria, 23 (5\%) secundaria, 5 $(41,7 \%)$ media superior y $3(25 \%)$ estudios profesionales. En relación al estado civil, $4(33,3 \%)$ dijeron ser solteros y $8(66,7 \%)$ casados.

\section{Núcleo central de la red semántica y peso semántico de las cinco palabras- estímulo}

A partir de los datos obtenidos por la técnica de redes semánticas naturales se obtuvo un valor J de 70 definidoras para la negación ante la enfermedad. El núcleo central de la red semántica fue: no aceptar que estoy mal, cobardía, no cuidarme, no ir al doctor, ocultar la verdad a los demás, auto-engañarme, miedo, no obtener información sobre la enfermedad, egoísta, no aceptar la realidad, ser negativa/o, ignorar, impotencia, querer que nadie se entere por temor a que me tengan lastima, y sentirme mejor (véase la tabla 1).

La ira ante la enfermedad obtuvo un valor J de 57 definidoras. El núcleo central de la red semántica estuvo conformado por: hacer corajes, enojo, Ilorar, impotencia al no comprenderla, usar malas palabras, no tener paciencia, desesperación, innecesaria, sentirse mal, falta de fe, tolerable, frustración, gritarle a todos, distanciarse de la familia y amigos, y los obstáculos que se encuentran (véase la tabla 2).

La negociación con la enfermedad tuvo un valor J de 57 definidoras. El núcleo central de la red semántica estuvo conformado por: prometerle cosas a Dios y a la virgen, cuidarme más, estar dispuesta(o) a todo, ser mejor, aceptarlo, sentirme mejor, prometí ser una mejor persona, tener una actitud positiva, sano, salir adelante, ganar, chantaje, adquirir información de la enfermedad, y ver lo que me conviene (véase la tabla 3).

La depresión ante la enfermedad obtuvo un valor J de 69 definidoras. El núcleo central de la red semántica estuvo conformado por: triste, Ilorar, sentirse sin apoyo, querer estar solo, desesperado, enfermarte más, querer morirse, no salir de la cama, no tener fe, tener pensamientos negativos, parte del proceso, no querer hacer nada, ser débil, preocuparme, y es mala (véase la tabla 4).

La aceptación de la enfermedad obtuvo un valor J de 70 definidoras. El núcleo central de la red semántica estuvo conformado por: ir al doctor a tratamientos, aceptarme a mí misma/o, primordial, una recuperación total, estar bien gracias a mi familia, 
Tabla 1. Valores M y FMG del núcleo central de la red semántica de negación de la enfermedad

\begin{tabular}{|l|c|c|}
\hline \multicolumn{1}{|c|}{ Conjunto SAM } & M & FMG \\
\hline No aceptar que estoy mal & 56 & 100 \\
Cobardía & 44 & 78,57 \\
No cuidarme (no tomar lo medicamentos, dieta) & 44 & 78,57 \\
No ir al doctor & 28 & 50 \\
Ocultar la verdad a los demás & 27 & 48,21 \\
Autoengañarme/mentirse a uno mismo & 26 & 46,43 \\
Miedo & 23 & 41,07 \\
No obtener información sobre la enfermedad & 21 & 37,50 \\
Egoísta & 21 & 37,50 \\
No aceptar la realidad & 20 & 35,71 \\
Ser negativa/o & 20 & 35,71 \\
Ignorar & 20 & 35,71 \\
Impotencia & 19 & 33,93 \\
Querer que nadie se entere por temor a que me tengan lastima & 18 & 32,14 \\
Sentirme mejor & 18 & 32,14 \\
\hline
\end{tabular}

Definidoras del conjunto $S A M=$ definidoras que se encuentran dentro de las primeras quince definidoras con mayor peso semántico, $M$ = peso semántico de cada definidora y $F M G$ = distancia semántica.

Tabla 2. Valores M y FMG del núcleo central de la red semántica de ira ante la enfermedad

\begin{tabular}{|l|c|c|}
\hline \multicolumn{1}{|c|}{ Conjunto SAM } & M & FMG \\
\hline Hacer corajes & 65 & 100 \\
Enojo & 40 & 61,54 \\
Llorar & 24 & 36,92 \\
Impotencia al no comprenderla & 20 & 30,77 \\
Usar malas palabras & 20 & 30,77 \\
No tener paciencia & 19 & 29,23 \\
Desesperación & 19 & 29,23 \\
Innecesaria & 18 & 27,70 \\
Sentirse mal & 17 & 26,15 \\
Falta de fe & 17 & 26,15 \\
Tolerable & 17 & 26,15 \\
Frustración & 17 & 26,15 \\
Gritarle a todos & 15 & 23,08 \\
Distanciarse de la familia y amigos & 14 & 21,54 \\
Los obstáculos que se encuentran & 10 & 15,39 \\
\hline
\end{tabular}

Definidoras del conjunto $S A M=$ definidoras que se encuentran dentro de las primeras quince definidoras con mayor peso semántico, $M=$ peso semántico de cada definidora y $F M G=$ distancia semántica. 
Tabla 3. Valores $\mathbf{M}$ y FMG del núcleo central de la red semántica de negociación con la enfermedad

\begin{tabular}{|l|c|c|}
\hline \multicolumn{1}{|c|}{ Conjunto SAM } & M & FMG \\
\hline Prometerle cosas a Dios y la virgen y pedirle: Vida, salud, & 102 & 100 \\
entendimiento y fuerzas & 34 & 33,33 \\
Tomar y aceptar los tratamientos & 34 & 33,33 \\
Cuidarme mas & 23 & 22,55 \\
Estar dispuesta a todo/ hacer lo que me corresponda & 22 & 21,57 \\
Ser mejor (tolerable y caritativa) & 20 & 19,61 \\
Aceptarlo & 17 & 16,67 \\
Sentirme mejor & 17 & 16,67 \\
Prometí ser una mejor persona & 16 & 15,69 \\
Tener una actitud positiva/pensar que todo va a estar bien & 13 & 12,74 \\
Sano & 12 & 11,76 \\
Salir adelante & 10 & 9,80 \\
Ganar & 10 & 9,80 \\
Chantaje & 10 & 9,80 \\
Adquirir información de la enfermedad & 10 & 9,80 \\
Ver lo que me conviene &
\end{tabular}

Definidoras del conjunto $S A M=$ definidoras que se encuentran dentro de las primeras quince definidoras con mayor peso semántico, $M=$ peso semántico de cada definidora y $F M G=$ distancia semántica.

\section{Tabla 4. Valores $\mathbf{M}$ y FMG del núcleo central de la red semántica de depresión ante la enfermedad}

\begin{tabular}{|l|c|c|}
\hline \multicolumn{1}{|c|}{ Conjunto SAM } & M & FMG \\
\hline Triste & 71 & 100 \\
Llorar & 59 & 83,10 \\
Sentirse sin apoyo & 41 & 57,75 \\
Querer estar solo/aislarse de los demás & 33 & 46,48 \\
Desesperada(o) & 32 & 45,07 \\
Enfermarte más & 28 & 39,44 \\
Muerte/ se quiere morir & 25 & 35,21 \\
No salir de la cama/querer estar todo el día acostado & 24 & 33,80 \\
No tener fe & 20 & 28,17 \\
Tener pensamientos negativos & 20 & 28,17 \\
Parte del proceso & 19 & 26,76 \\
No querer hacer nada & 19 & 26,76 \\
Ser débil & 19 & 26,76 \\
Preocuparme & 19 & 26,76 \\
Es mala & 17 & 23,94 \\
\hline
\end{tabular}

Definidoras del conjunto $S A M=$ definidoras que se encuentran dentro de las primeras quince definidoras con mayor peso semántico, $M$ = peso semántico de cada definidora y $F M G$ = distancia semántica. 


\section{Tabla 5. Valores M y FMG del núcleo central de la red semántica de aceptación de la enfermedad}

\begin{tabular}{|l|c|c|}
\hline \multicolumn{1}{|c|}{ Conjunto SAM } & M & FMG \\
\hline Ir al doctor a tratamientos & 57 & 100 \\
Aceptarme a mi misma & 37 & 64,91 \\
Primordial/lo más importante & 27 & 47,37 \\
Una recuperación total/Sanar & 25 & 43,86 \\
Estar bien gracias a mi familia & 23 & 40,36 \\
Aceptar todo el proceso & 23 & 40,36 \\
Quererme a mi misma & 20 & 35,09 \\
Paciencia & 20 & 35,09 \\
Aceptar con resignación & 19 & 33,33 \\
Aceptar que lo tengo & 19 & 33,33 \\
No importa que grave es la enfermedad & 19 & 33,33 \\
Tomar las cosas como son & 19 & 33,33 \\
Tener fe & 18 & 31,58 \\
Armarme de valor/ ser fuerte ante la situación & 18 & 31,58 \\
Madurez & 18 & 31,58 \\
\hline
\end{tabular}

Definidoras del conjunto $S A M=$ definidoras que se encuentran dentro de las primeras quince definidoras con mayor peso semántico, $M$ = peso semántico de cada definidora y $F M G=$ distancia semántica.

aceptar todo el proceso, quererme a mí misma/o, paciencia, aceptar con resignación, aceptar que lo tengo, no importa qué grave es la enfermedad, tomar las cosas como son, tener fe, armarme de valor, y madurez (véase la tabla 5).

\section{Diseño de la escala de las fases del proceso del duelo}

La redacción de los ítems se derivó del conjunto SAM, es decir, de las primeras 15 palabras con mayor peso semántico o valor $\mathrm{M}^{(6)}$ y a partir de consideraciones teóricas. La escala quedó conformada por 67 ítems y cinco dimensiones, una para cada fase del duelo propuesta por KüblerRoss $^{(2)}$. La fase de negación de la enfermedad quedó conformada por 16 ítems, la fase de ira por 12 ítems, la fase de negociación por 12 ítems, la fase de depresión por 12 ítems y la fase de aceptación de la enfermedad por 15 ítems (véanse Tablas de la 6 a la 10).
Por falta de congruencia o adecuación teórica se ignoraron tres definidoras del núcleo central de la red semántica de negación (no obtener información sobre la enfermedad, ser egoísta, y ser negativa), diez definidoras del núcleo central de ira (no tener paciencia, desesperación, innecesaria, sentirse mal, falta de fe, tolerable, frustración, gritarle a todos, distanciarse de la familia y amigos, y los obstáculos que se encuentran), ocho definidoras de pacto/ negociación (tomar y aceptar los tratamientos, estar dispuesta a todo/hacer lo que me corresponda, ser mejor, tolerable y caritativa, aceptarlo, ganar, chantaje, adquirir información de la enfermedad, y ver lo que me conviene), seis definidoras de depresión (desesperación, enfermarte más, parte del proceso, ser débil, preocuparme, y es mala) y seis definidoras de aceptación (ir al doctor a tratamientos, primordial/ lo más importantes, paciencia, no importa que grave es la enfermedad, armarme de valor/ser fuerte ante la situación, y madurez). 


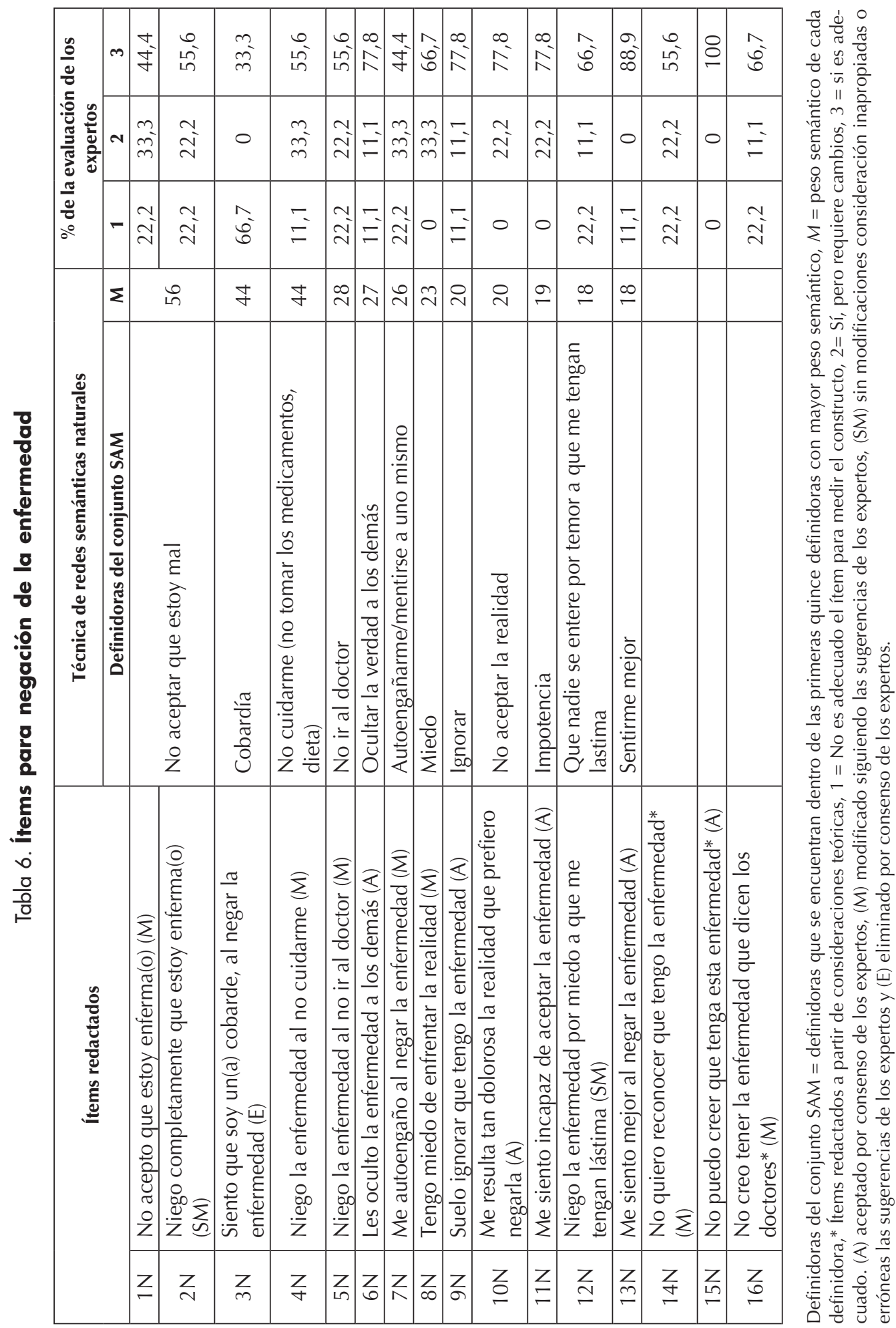




\begin{tabular}{|c|c|c|c|c|c|c|c|c|c|c|c|c|c|}
\hline \multirow{3}{*}{ 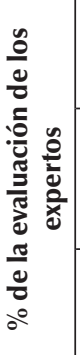 } & $m$ & $\stackrel{\infty}{N}$ & ڤ్ & $\begin{array}{l}\hat{0} \\
0^{\prime}\end{array}$ & ڤ્ & $\stackrel{\infty}{\wedge}$ & $\begin{array}{l}9 \\
\infty \\
\infty\end{array}$ & $\begin{array}{l}\text { a } \\
\infty \\
\infty\end{array}$ & $\stackrel{\infty}{N}$ & $\begin{array}{l}a \\
\infty \\
\infty\end{array}$ & $\stackrel{\infty}{N}$ & $\stackrel{8}{\circ}$ & $\begin{array}{l}\text { a } \\
\infty \\
\infty\end{array}$ \\
\hline & $N$ & 0 & 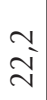 & 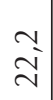 & $\mp$ & ָ̃ & $\mp$ & 0 & $\bar{E}$ & $\bar{E}$ & 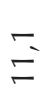 & 0 & 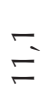 \\
\hline & - & 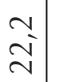 & $\Xi$ & 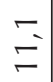 & $\tilde{N}$ & 0 & 0 & $\mp$ & 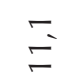 & 0 & $\Xi$ & 0 & 0 \\
\hline \multirow[b]{2}{*}{ 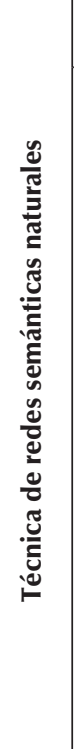 } & $\Sigma$ & 능 & $\stackrel{P}{+}$ & $\stackrel{ \pm}{\sim}$ & 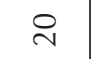 & 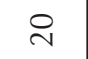 & & & & & & & \\
\hline & 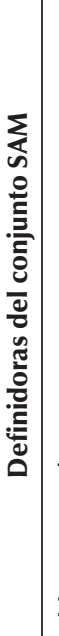 & 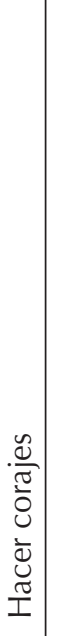 & $\begin{array}{l}\frac{\circ}{2} \\
\stackrel{ }{ \pm}\end{array}$ & $\frac{\bar{\Xi}}{\bar{\Xi}}$ & 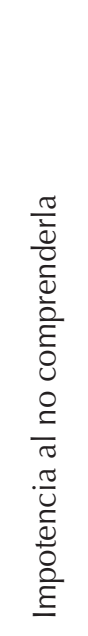 & 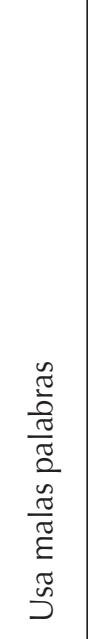 & & & & & & & \\
\hline \multirow[t]{2}{*}{ 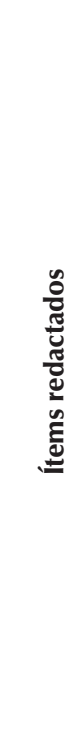 } & & 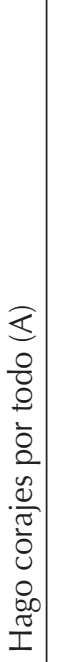 & 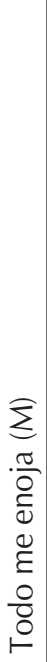 & 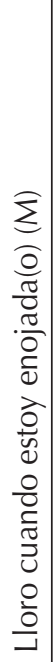 & 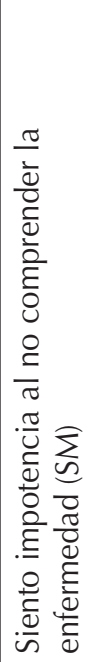 & 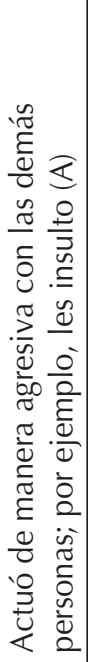 & 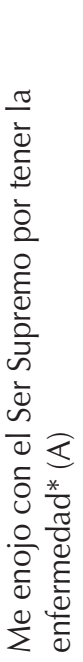 & 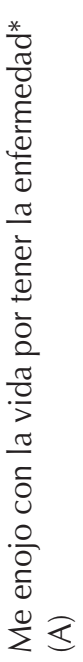 & 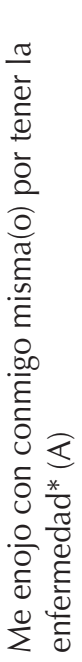 & 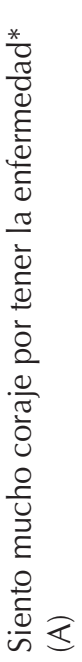 & 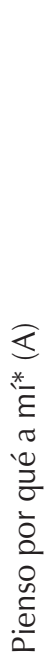 & 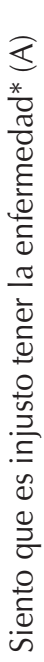 & 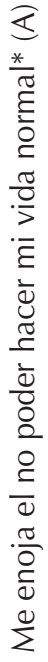 \\
\hline & & $\bar{F}$ & $\bar{v}$ & $\bar{m}$ & $\bar{\sigma}$ & $\bar{n}$ & $\bar{\sigma}$ & $\bar{\Lambda}$ & $\bar{\infty}$ & ন & 으 & Е & $\bar{\beth}$ \\
\hline
\end{tabular}

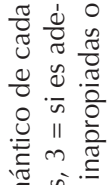

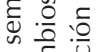

论

II $\frac{2}{2} \cdot \frac{2}{5}$

$<$ 웡

岂 을

$\stackrel{\pi}{2}$

济语

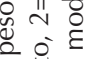

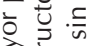

है

ठิ $\frac{u}{0}$

ป :

응 랑

은 은

ष

훤

๘ 윤

式 ज

$\frac{\pi}{2} \frac{\pi}{8}$

뜨 \& 응 응

은 원

임 110

당

는

वे

此

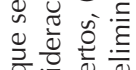

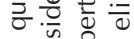

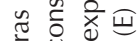

응 응 으 웅

言定

II

$\sum \pi$ v

is $\frac{0}{8} 8$

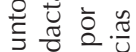

응 웡

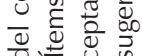

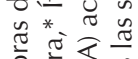

응 흥

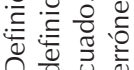




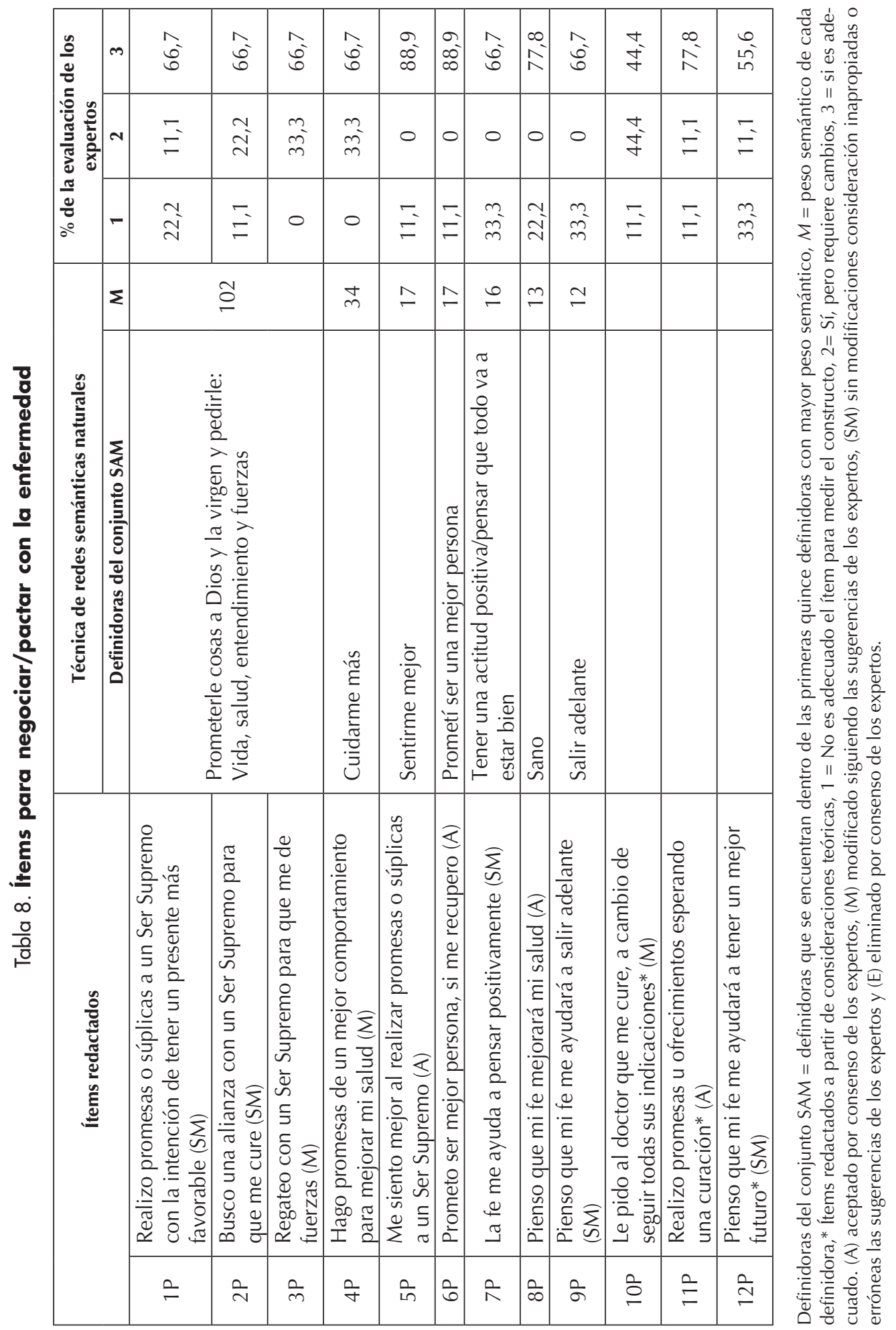




\begin{tabular}{|c|c|c|c|c|c|c|c|c|c|c|c|c|c|}
\hline \multirow{3}{*}{ 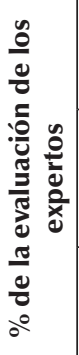 } & n & $\begin{array}{l}9 \\
\infty \\
\infty\end{array}$ & $\stackrel{\circ}{\circ}$ & $\widehat{\overbrace{}}$ & ○ & ڤ్ & $\stackrel{\infty}{\wedge}$ & $\stackrel{\infty}{N}$ & $\stackrel{\infty}{N}$ & $\begin{array}{l}9 \\
\infty \\
\infty\end{array}$ & $\widehat{0}$ & $\stackrel{\infty}{\wedge}$ & $\stackrel{\circ}{\circ}$ \\
\hline & N & E & 0 & ָ̃ & 0 & $F$ & $\mp$ & $\bar{F}$ & $\begin{array}{l}\sim \\
\sim \\
\sim\end{array}$ & E & 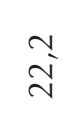 & $\underset{v}{N}$ & 0 \\
\hline & - & 0 & 0 & $\Xi$ & 0 & $\underset{\sim}{\sim}$ & 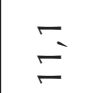 & Е & 0 & 0 & $\bar{F}$ & 0 & 0 \\
\hline \multirow[b]{2}{*}{ 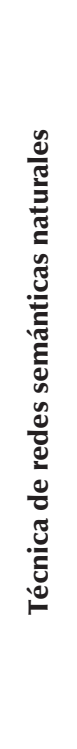 } & $\Sigma$ & $\bar{\lambda}$ & ก) & $\bar{\nabla}$ & $m$ & $\stackrel{\llcorner}{\mathcal{N}}$ & $\stackrel{\sim}{\sim}$ & $\stackrel{\ominus}{\sim}$ & $\stackrel{\curvearrowright}{\nu}$ & $\Omega$ & & & \\
\hline & 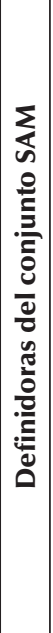 & 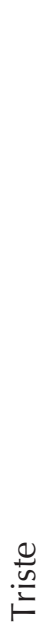 & 흠 & 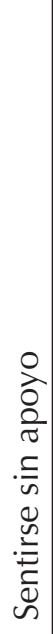 & 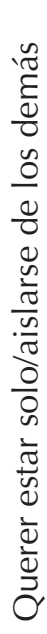 & 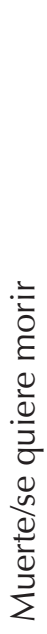 & 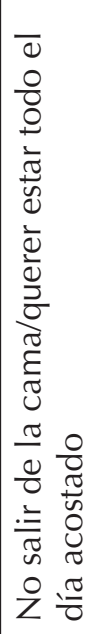 & 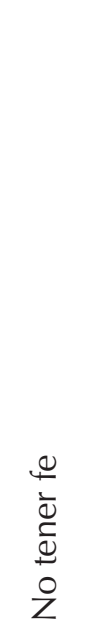 & 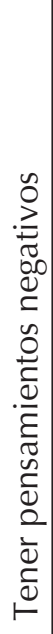 & 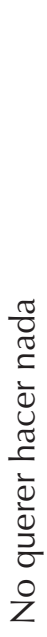 & & & \\
\hline \multirow{2}{*}{\multicolumn{2}{|c|}{ 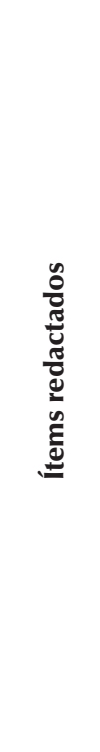 }} & 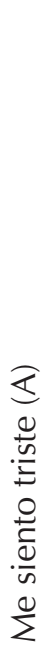 & 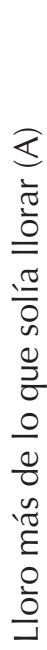 & 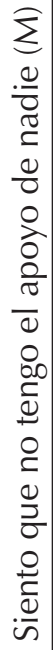 & 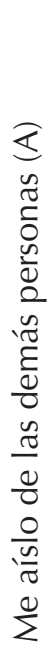 & 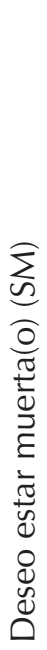 & 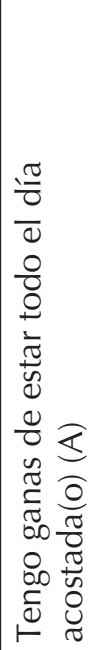 & 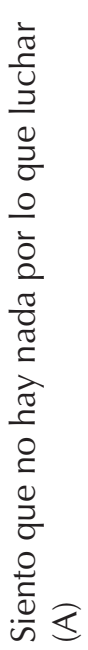 & 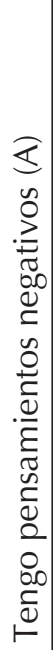 & 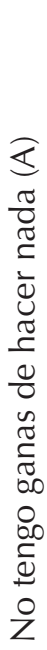 & 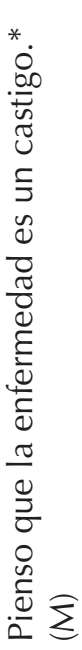 & 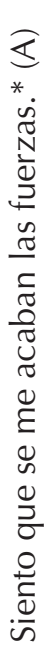 & 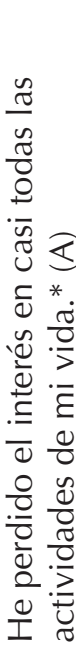 \\
\hline & & $\stackrel{-}{=}$ & $\stackrel{\sim}{v}$ & $\stackrel{\circ}{n}$ & $\supsetneq$ & 늠 & 0 & $\stackrel{\cap}{\wedge}$ & $\stackrel{\infty}{\infty}$ & ๙ & $\stackrel{0}{\circ}$ & $\stackrel{口}{\simeq}$ & 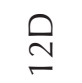 \\
\hline
\end{tabular}

苋 $\frac{d}{0} \frac{0}{\pi}$

过 $\frac{\pi}{0}$

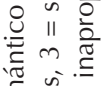

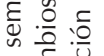

원

$\therefore$ 造

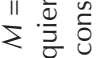

0.

竞 일

谣

일

$\stackrel{0}{\circ} \varepsilon$

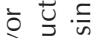

ฮี

○。

$\because=\frac{0}{0}$

을 앙

进䒕

$\frac{2}{0}$

ป气

휭

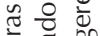

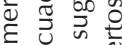

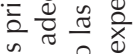

드 \& 용

은 웧

잉 11 .

可

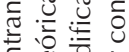

¿

Uิ

क ज

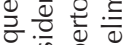

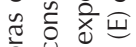

을 웡으 홍

言产

元 잉

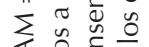

is 웡

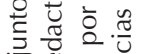

흐웡

过. है

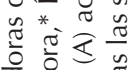

旁 


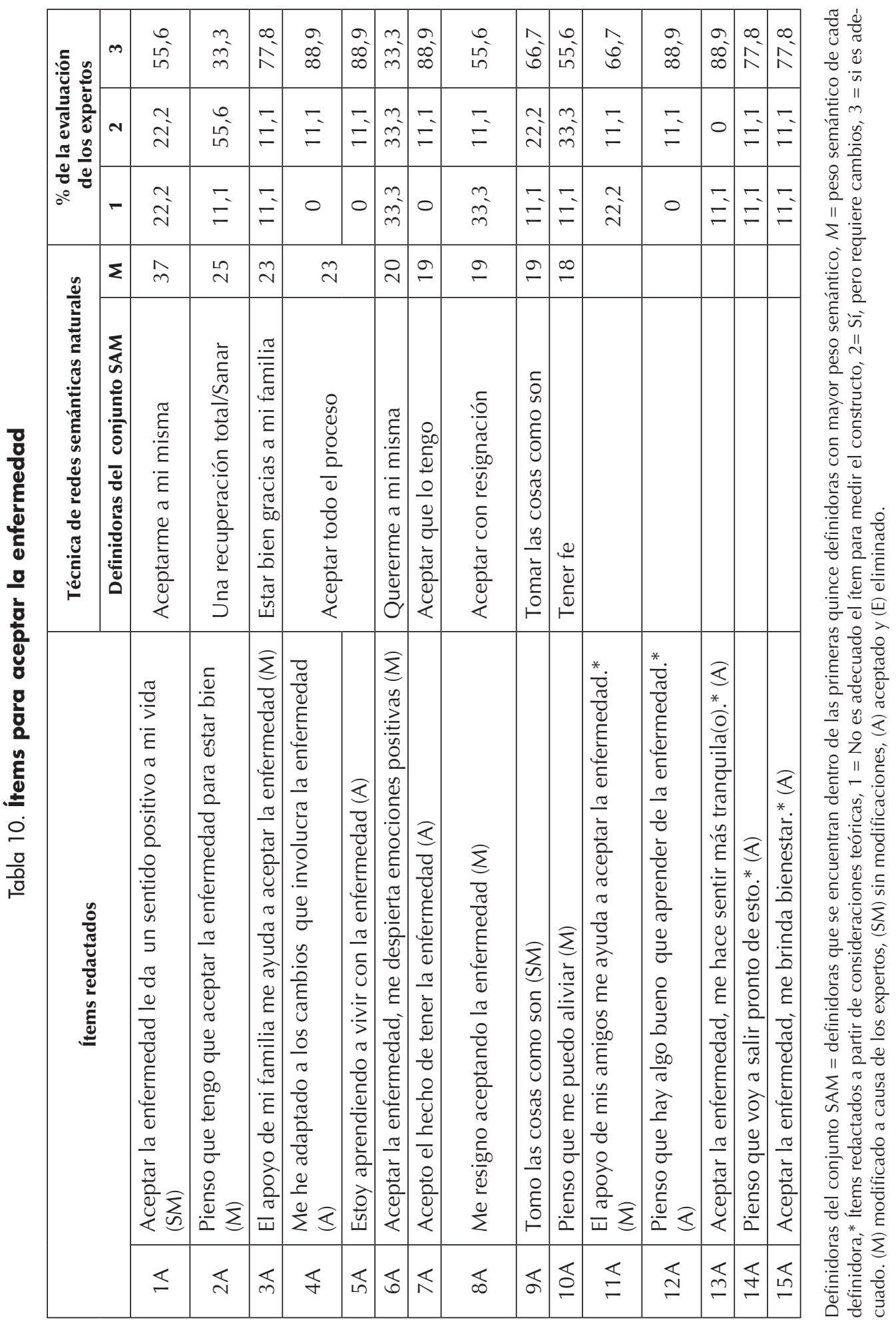




\section{Validez de contenido: jucio de expertos}

Desde la valoración de los 9 expertos, 36 ítems se aceptaron debido a que el valor 3 (sí es adecuado) alcanzó un porcentaje de 77,8 (al menos 7 expertos), un ítem se rechazo debido a que el valor 1 (no es adecuado) alcanzó un porcentaje de 66,7 (al menos 6 expertos). En los 30 ítems restantes los expertos consideraron que se aceptaban con cambios, en 19 ítems se retomaron las sugerencias, y en 11 ítems se dejaron los mismos sin cambios debido a que se consideraron inapropiadas o erróneas las sugerencias (véanse las tablas de la 6 a la 10).

Por lo tanto, la propuesta final de la escala de fases del duelo tras la modificación de su redacción desde la valoración y las sugerencias de los expertos, quedó conformada por 66 ítems, 15 ítems para la fase de negación $(1,6,15,20,25,30,35$, 40, 45, 50, 55, 60, 62, 64 y 66), 12 ítems para la fase de ira $(2,7,11,16,21,26$, $31,36,41,46,51$ y 56), 12 ítems para la fase pacto o negociación $(3,8,12,17,22$, $27,32,37,42,47,52$ y 57), 12 ítems para la fase depresión $(4,9,13,18,23,28,33$, $38,43,48,53$ y 58$)$, y 15 ítems para la fase de aceptación de la enfermedad $(5,10,14$, 19, 24, 29, 34, 39, 44, 49, 54, 59, 61, 63 y 65) (véase Anexo 1).

\section{DISCUSIÓN}

\section{El significado psicológico de la negación ante la enfermedad}

El significado psicológico que se encontró ante la negación de la enfermedad en los pacientes y cuidadores primarios es similar al que propuso Kübler-Ross ${ }^{(2)}$, considerándolo como la imposibilidad de reconocer el hecho de que se padezca la enfermedad. Moyer y Levine ${ }^{(3)}$ destacaron la necesidad de distanciarse y evitar pensar y hablar de la enfermedad al estudiar el significado de la negación entre pacientes con cáncer. Precisamente estas definidoras también se encontraron en el presente estudio.

En la mayoría de los estudios la negación inicial cumple con una función amortiguadora y se considera como una defensa provisional para afrontar la situación ${ }^{(2,27,28)}$. Asimismo, varios investigadores señalan que la negación es una estrategia adaptativa para proteger a la persona de eventos, pensamientos, sentimientos o de información dolorosa o amenazante ${ }^{(5,29)}$, permitiéndole un mayor tiempo para procesar la situación, lo cual disminuye la ansiedad $^{(30)}$.

No obstante, también se encontraron definidoras que hacen énfasis en una negación desadaptativa, la cual se manifiesta en el retraso de la búsqueda de tratamiento médico, en la falta de adherencia al tratamiento y en la ausencia de obtención de información sobre la enfermedad. Otros autores al describir esta fase también han hallado estos mismos contenidos ${ }^{(5,27,30)}$. Debido a todo esto, muchos profesionales de la salud suelen considerar que el uso de la negación predice una mala evolución de la enfermedad ${ }^{(31)}$.

\section{El significado psicológico de la ira ante la enfermedad}

Entre las definidoras obtenidas para la ira ante la enfermedad se encontraron reacciones emocionales de rabia, enojo, hostilidad y agresividad por haber perdido la salud. Se halló que la ira estaba dirigida hacia todos en general, hacia la familia, amigos y obstáculos que se encuentran. Kübler-Ross ${ }^{(2)}$ observó, de forma semejante, que la ira era dirigida contra la persona misma y su entorno tras una fase de negación.

Pérez, Acosta, Megías y Lupiáñez señalaron que existe una fuerte correlación positiva entre la ansiedad, la depresión y la $\mathrm{ira}^{(32)}$. Para Sandín estas tres emociones 
negativas son especialmente dañinas para la salud, ya que incrementan la vulnerabilidad hacia la enfermedad, perturban el funcionamiento del sistema inmune, agravan el dolor e incrementan el riesgo de muerte $^{(33)}$.

\section{El significado psicológico del pacto/ negociación con la enfermedad}

Como también refiere Kübler-Ross ${ }^{(2)}$, a la palaba-estímulo pacto/negociación se asoció el llegar a un acuerdo con Dios, allegados o ellos mismos, prometiendo alcanzar metas personales, para prolongar la vida y recuperación. Asimismo se encontró que los pacientes y cuidadores primarios intentan pensar positivamente, dirigiendo su mirada a la espiritualidad y buscando una alianza con un Ser Supremo.

En este sentido, el pacto/negociación está relacionado con la posibilidad de alcanzar metas, deseos, expectativas y objetivos orientados hacia el futuro, lo cual otorga a los pacientes y parientes una mayor motivación, fuerza y dirección. Los participantes señalan que el pacto proporciona un sentido a la vida y a la existencia, asimismo da más fuerza ante la adversidad, promoviendo una orientación positiva. Como indican algunos autores ${ }^{(34,35)}$, esta orientación se manifiesta a través de mayores expectativas de vida y calidad de vida, esperanza de ser curado del cáncer, mayor control de los síntomas, no tener recaídas, reinserción en la vida social y laboral, disfrutar de la vida y morir con dignidad, entre otros deseos.

\section{El significado psicológico de la depresión ante la enfermedad}

Coincidiendo con las características mencionadas por Kübler-Ross para la fase de depresión ante la enfermedad ${ }^{(2)}$, se haIlaron como definidoras la presencia de tristeza, pensamientos negativos, deseos de muerte, aislamiento social y una actitud de claudicación ante la enfermedad. En este estudio prevalecen los aspectos afectivos, cognitivos y sociales. González y Valdez ${ }^{(6)}$ señalan, en su estudio de redes semánticas del concepto de depresión, que los psicólogos asocian estas características con más frecuencia que los médicos. Estos últimos dan más énfasis a los aspectos biológicos, como cambios de apetito o peso, del sueño y de la actividad psicomotora. Así los psicólogos están más próximos a la imagen de la depresión que tienen los pacientes y parientes que los médicos.

González y Valdez consideran que la falta de fe en salir adelante es uno de los principales síntomas de la depresión ${ }^{(6)}$. Además señalan que la depresión comienza como una imposibilidad de enfrentar adecuadamente la situación adversa, la cual tiene como base los miedos básicos del ser humano: el miedo a la muerte y a quedarse solo, produciendo un estado de desesperación, que al no ser controlado genera un cierto grado de desesperanza, lo cual constituye el punto de partida hacia la depresión. Afín a esta propuesta se encontraron definidoras como la desesperación y la falta de fe con un peso semántico intermedio dentro del conjunto SAM.

\section{El significado psicológico de la aceptación de la enfermedad}

Entre las definidoras obtenidas para la aceptación de la enfermedad se encontró una actitud responsable de lucha y supervivencia, tal como lo menciona KüblerRoss ${ }^{(2)}$; es decir, aceptar la enfermedad, pero sin que el paciente se siente a observar pasivamente la misma. En esta fase el hecho de saberse enfermo constituye lo necesario para alcanzar un estado de salud estable ${ }^{(36)}$.

Kübler-Ross hacía énfasis en que aceptar la enfermedad no debía confundirse 
con la resignación ${ }^{(2)}$; no obstante, entre las definidoras de aceptación se encontró el resignarse. Precisamente, otros autores definen el término resignación como una estrategia de afrontamiento emocional pasiva que implica la aceptación de la situación como algo inamovible ${ }^{(7)}$ o equiparan el término a estoicismo, en el cual la máxima o norma a seguir es soportar heroicamente el sufrimiento ${ }^{(9)}$. Ya sea por la pasividad o aguantar calladamente, el resignarse no permite vivir en paz o armonía con la enfermedad, por el contrario genera gran malestar emocional ${ }^{(37)}$.

Por su parte, Isla, Moncho, Guasch y Torras $^{(8)}$ señalan que es más realista hablar de adaptación a la enfermedad que de aceptación, puesto que los procesos de pérdida son constantes. Los pacientes consiguen adaptarse a la enfermedad y al tratamiento, aunque manifiestan que esta percepción de equilibrio es inestable y que cada complicación crónica genera nuevos procesos de duelo, manifestados por sentimientos de ira y tristeza.

Como limitaciones del estudio debe señalarse que se trabajó con una muestra reducida intencional. No obstante, la técnica asociativa empleada, al no poner límite de número a las palabras definidoras emitidas, facilita obtener la saturación de contenidos con pocos $\operatorname{casos}^{(23)}$. Además la variedad de familiares participantes fue amplia, entre los cuales había hijos, hermanas, una cuñada y un padre. Aunque en este artículo se reporta la exploración del campo semántico por medio de una sólo técnica cualitativa, debe mencionarse que también se obtuvieron datos desde un cuestionario de preguntas abiertas. Debido a la convergencia de resultados y la extensión que requería exponer todo el material obtenido, se redujo el reporte a la técnica más estructurada $y$, por ende, que facilita el mismo.

En conclusión, los significados psicológicos de las cinco fases del duelo son afi- nes a los propuestos por Kübler-Ross ${ }^{(2)}$. No obstante, hay ciertos aspectos diferenciales como el hecho de que algunos pacientes $y$ parientes ven la negación como desadaptativa cuando Kübler-Ross(2) indica que es una defensa necesaria para la adaptación a la enfermedad; o que la fase final para algunos pacientes y parientes consiste en una resignación estoica en lugar de la actitud de lucha activa que propone KüblerRoss $^{(2)}$. Derivada de estos contenidos junto con consideraciones teóricas y sugerencias de expertos, se desarrolla la Escala de las Fases del Duelo conformada por 66 ítems y cinco dimensiones. Los 66 ítems están redactados de manera directa; es decir que a mayor puntuación, mayor es la frecuencia en la que experimentan cada una de las fases del duelo ante la enfermedad. Se propone que el rango de respuesta sea de cinco puntos (de $1=$ nunca a $5=$ siempre). Por lo tanto, para las fases de negación y aceptación de la enfermedad (con 15 ítems cada una de las fases) la puntuación variará de 15 a 75 puntos, y para las fases de ira, pacto y depresión ante la enfermedad (con 12 ítems cada una de las fases) la puntuación variará de 12 a 60 puntos. En una investigación posterior se pretende realizar la selección final de los ítems con base en sus propiedades psicométricas.

Así se sugiere estudiar las propiedades de consistencia, estabilidad y validez de la Escala de las Fases del Duelo (EFD-66) en muestras de pacientes y parientes tanto en México como en otros países hispanohablantes, considerando la estructura teórica de 5 dimensiones correlacionadas o secuenciales.

\section{Agradecimientos}

Este trabajo fue realizado con el apoyo de la beca doctoral otorgada a la primera autora por el CONACYT. Se agradece a los pacientes y a la Cruz Rosa, A.B.P., así como a los expertos que formaron parte 
de la validación de contenido: Eduardo Elizondo, Evelyn García, Vereniz Moguel, Manuel Nava, Iris Ochoa, Janeth Ramos, Guillermo Torres, Julián Villareal y Tania Zertuche.

\section{REFERENCIAS BIBLIOGRÁFICAS}

1. Bowlby J. Processes of mourning. Int J Psychoanal 1961; 42: 317-39.

2. Kübler-Ross E. On Death and Dying. New York: Macmillan, 1969.

3. Moyer A, Levine EG. Clarification of the conceptualization and measurement of denial in psychosocial oncology research. Ann Behav Med 1998; 20(3):149-60. Doi: 10.1007/BF02884955.

4. Wheeler S, Louann L. Denial: A conceptual analysis. Arch Psychiat Nurs 1999; 13(6): 311-20. Doi: 10.1016/S08839417(99)80063-6.

5. Rabinowitz T, Peirson R. "Nothing is wrong, Doctor": Understanding and managing denial in patients with cancer. Cancer Invest 2006; 24(1):68-76. Doi: 10.1080/07357900500449678.

6. González S, Valdez JL. Significado psicológico de la depresión en médicos y psicólogos. Psicol Salud 2005;15(2):257-62.

7. Rodríguez-Marín J, Terol MC, López-Roig S, Pastor MA. Evaluación del afrontamiento del estrés: propiedades psicométricas del Cuestionario de Formas de Afrontamiento de Acontecimientos Estresantes. Rev Psicol Salud 1992;4:59-84.

8. Isla P, Moncho J, Guasch O, Torras A. Proceso de adaptación a la diabetes mellitus tipo 1 (DM1). Concordancia con las etapas del proceso de duelo descrito por KüblerRoss. Rev Endocrinol Nutr 2008;55(2):7883.

9. Sánchez R, Dos-Santos MA. Cáncer de mama, pobreza y salud mental: respuesta emocional a la enfermedad en mujeres de camadas populares. Rev Latino-Am Enfermagem 2007;15:786-791. Doi: 10.1590/ S0104-11692007000700012.
10. Blanco L, Librada S, Rocafort J, Cabo R, Galea T, Alonso ME. Perfil del cuidador principal del enfermo en situación terminal y análisis del riesgo de desarrollar duelo patológico. Med Paliat 2007;14(3):1-5.

11. Lobb EA, Kristjanson LJ, Aoun SM, Monterosso L, Halkett GKB, Davies, A. Predictors of Complicated Grief: A Systematic Review of empirical studies. Death Stud 2010;34(8):673-98. Doi: 10.1080/07481187.2010.496686.

12. Tomarken A, Holland J, Schachter S, Vanderwerker L, Zuckerman E, Nelson, C, et al. Factors of complicated grief pre-death in caregivers of cancer patients. J PsychoOncol 2008;17(2):105-11. Doi: 10.1002/ pon.1188.

13. Bonanno GA, Wortman CB, Lehman DR, Tweed RG, Haring M, Sonnega J, et al. Resilience to loss and chronic grief: A prospective study from preloss to 18-months postloss. J Pers Soc Psychol 2002;83(5):1150-64. Doi: 10.1037/00223514.83.5.1150.

14. Cabodevilla, I. Las pérdidas y sus duelos. Anales Sis San Navarra 2007;30(3):16376.

15. Cordero MA, Palacios P, Mena P, Medina L. Perspectivas actuales del duelo en el faIlecimiento de un recién nacido. Rev Chil Pediatr 2004;75(1): 67-74.

16. Maciejewski PK, Zhang B, Block SD, Prigerson HG. An Empirical examination of the stage theory of grief. J Am Med Assoc 2007;297(7):716-24.

17. Sánchez R, Gutiérrez C, Valencia JA. La muerte de un ser querido: validez y confiabilidad de una medida de regulación emocional. Rev Mex Invest Psicol 2011; 3(1): 72-84.

18. Sanders CM, Mauger PA, Strong PN. A manual for the Grief Experience Inventory. North Carolina: The Center for the Study of Separation and Loss, 1985.

19. Faschingbauer TR, De Vaul RA, Zissok S. Development of the Texas Inventory of Grief. Am J Psychiatry 1977;134: 696-8. 
20. Newman I, Smith P, Griffith D, Maloney $P$, Dambrot $F$, Sterns $H$, et al. The alpha-omega scale: the measurement of stress situation coping styles. Ohio J Sci 1983;83(5):241-6.

21. Worden JW. El tratamiento del duelo: asesoramiento psicológico y terapia (Segunda edición). Barcelona: Paidós, 2010.

22. Valdez JL. Las redes semánticas naturales en psicología social. Mexico: Universidad Autónoma del Estado de México, 1998.

23. Valdez JL. Las redes semánticas naturales, usos y aplicaciones en psicología social. México: Universidad Autónoma del Estado de México, 2005.

24. Figueroa N, González E, Solís V. Una aproximación al problema del significado: las redes semánticas. Rev Latinoam Psicol 1981;13(3):447-58.

25. Szalay L, Bryson J. Measurement of Psychocultural Distance: A comparison of americans blacks and whites. J Pers Soc Psychol 1973;26(2):166-77.

26. Sociedad Mexicana de Psicología [SMP]. Código Ético del Psicólogo. México: TriIlas, 2007.

27. Greer S. The management of denial in cancer patients. Rev Oncol 1992; 6(12): 33-6.

28. Secoli SR, Pezo MC, Rolim MA, Machado AL. El cuidado de la persona con cáncer: un abordaje psicosocial. Rev Index Enferm 2005;14(51):34-9.

29. Vos MS, De Haes JCJM. Denial in cancer patients, an explorative review. Psychooncology 2007;16(1):12-25. Doi: 10.1002/ pon.1051.
30. Kreitler S. Denial in cancer patients psychosocial issues. Cancer Investig 1999;17(7):514-34.

31. Morley C. The use of denial by patients with cancer. J Prof Nurs 1997;12(5):380-1.

32. Pérez C, Acosta A, Megías J, Lupiáñez J. Evaluación de las dimensiones de valencia, activación, frecuencia subjetiva de uso y relevancia para la ansiedad, la depresión y la ira de 238 sustantivos en una muestra universitaria. Psicol 2010;31(2):241-73.

33. Sandín B. Papel de las emociones negativas en el trastorno cardiovascular: un análisis crítico. Rev Psicopatol Psicol Clín 2002;7(1):1-18.

34. De León V, Cuetos C. Tanatología: Una perspectiva distinta de la muerte. Bol Med 2004;5(1):13-9.

35. Llantá MC, Massip C, Martínez Y. La significación de la esperanza en el paciente oncológico. Medicina Salud y Sociedad 2012; 2(3). En línea [Acceso 10 de enero de 2013] Disponible en: http://www. medicinasaludysociedad.com/site/images/ stories/2_3/May12EsperanzaPacientesOncologicos.pdf

36. Broche $Y$, Medina WR. Resiliencia y afrontamiento: Una visión desde la psicooncología. Psicología.com 2011. En línea [Acceso el 1 de febrero de 2013] Disponible en: http://www.psiquiatria.com/bibliopsiquis/bitstream/10401/4068/3/psicologiacom_2011_15_17.pdf

37. Moral J, Valdez JL, Alvarado BG. Instrumentación métrica del concepto de paz. Daena: International Journal of Good Conscience 2011;6(1):11-39. 


\section{Anexo 1. Escala de las Fases del Duelo (EFD-66)}

Se presenta la propuesta final de la escala de fases del duelo con 66 ítems tras la modificación de su redacción desde la valoración y las sugerencias de los expertos.

Instrucciones: Encierre en un circulo con qué frecuencia experimenta estas acciones, sentimientos y pensamientos en relación a su proceso de enfermedad.

\begin{tabular}{|c|c|c|c|c|}
\hline 1 & 2 & 3 & 4 & 5 \\
\hline Nunca & Pocas veces & A veces & Casi siempre & Siempre \\
\hline
\end{tabular}

\begin{tabular}{|c|c|c|c|c|c|c|}
\hline F.E. & Ítem & \multicolumn{5}{|c|}{ Frecuencia } \\
\hline $1 \mathrm{~N}$ & 1. No creo que estoy enferma(o). & 1 & 2 & 3 & 4 & 5 \\
\hline 11 & 2. Hago corajes por todo. & 1 & 2 & 3 & 4 & 5 \\
\hline $1 \mathrm{P}$ & $\begin{array}{l}\text { 3. Realizo promesas o súplicas a un Ser Supremo con la } \\
\text { intención de tener un presente más favorable. }\end{array}$ & 1 & 2 & 3 & 4 & 5 \\
\hline $1 \mathrm{D}$ & 4. Me siento triste. & 1 & 2 & 3 & 4 & 5 \\
\hline $1 \mathrm{~A}$ & 5. Aceptar la enfermedad le da un sentido positivo a mi vida. & 1 & 2 & 3 & 4 & 5 \\
\hline $2 \mathrm{~N}$ & 6. Niego completamente que estoy enferma(o). & 1 & 2 & 3 & 4 & 5 \\
\hline 21 & 7. Cualquier cosita me enoja. & 1 & 2 & 3 & 4 & 5 \\
\hline $2 \mathrm{P}$ & 8. Busco una alianza con un Ser Supremo para que me cure. & 1 & 2 & 3 & 4 & 5 \\
\hline $2 \mathrm{D}$ & 9. Lloro más de lo que solía llorar. & 1 & 2 & 3 & 4 & 5 \\
\hline $2 \mathrm{~A}$ & 10. Aceptar la enfermedad me permite estar bien. & 1 & 2 & 3 & 4 & 5 \\
\hline 31 & 11. Lloro de coraje. & 1 & 2 & 3 & 4 & 5 \\
\hline $3 \mathrm{P}$ & 12. Negociar con un Ser Supremo me da fuerzas. & 1 & 2 & 3 & 4 & 5 \\
\hline $3 \mathrm{D}$ & 13. Siento que nadie me apoya. & 1 & 2 & 3 & 4 & 5 \\
\hline $3 \mathrm{~A}$ & $\begin{array}{l}\text { 14. El apoyo de mi familia me ayuda a aceptar la enferme- } \\
\text { dad. }\end{array}$ & 1 & 2 & 3 & 4 & 5 \\
\hline $4 \mathrm{~N}$ & 15. No necesito cuidarme, pues no estoy enfermo. & 1 & 2 & 3 & 4 & 5 \\
\hline 41 & 16. Siento impotencia al no comprender la enfermedad. & 1 & 2 & 3 & 4 & 5 \\
\hline $4 \mathrm{P}$ & 17. Prometo portarme mejor para mejorar mi salud. & 1 & 2 & 3 & 4 & 5 \\
\hline $4 \mathrm{D}$ & 18. Me aíslo de las demás personas. & 1 & 2 & 3 & 4 & 5 \\
\hline $4 \mathrm{~A}$ & $\begin{array}{l}\text { 19. Me he adaptado a los cambios que involucra la enfer- } \\
\text { medad. }\end{array}$ & 1 & 2 & 3 & 4 & 5 \\
\hline $5 \mathrm{~N}$ & 20. No voy al doctor, pues no estoy enfermo. & 1 & 2 & 3 & 4 & 5 \\
\hline 51 & $\begin{array}{l}\text { 21. Actuó de manera agresiva con las demás personas; por } \\
\text { ejemplo, } \\
\text { les insulto. }\end{array}$ & 1 & 2 & 3 & 4 & 5 \\
\hline $5 \mathrm{P}$ & $\begin{array}{l}\text { 22. Me siento mejor al realizar promesas o súplicas a un Ser } \\
\text { Supremo. }\end{array}$ & 1 & 2 & 3 & 4 & 5 \\
\hline $5 \mathrm{D}$ & 23. Deseo estar muerta(o). & 1 & 2 & 3 & 4 & 5 \\
\hline $5 \mathrm{~A}$ & 24. Estoy aprendiendo a vivir con la enfermedad. & 1 & 2 & 3 & 4 & 5 \\
\hline $6 \mathrm{~N}$ & 25. Les oculto la enfermedad a los demás. & 1 & 2 & 3 & 4 & 5 \\
\hline 61 & 26. Me enojo con el Ser Supremo por tener la enfermedad. & 1 & 2 & 3 & 4 & 5 \\
\hline
\end{tabular}




\begin{tabular}{|c|c|c|c|c|c|c|}
\hline F.E. & Ítem & \multicolumn{5}{|c|}{ Frecuencia } \\
\hline $6 \mathrm{P}$ & 27. Prometo ser mejor persona, si me recupero. & 1 & 2 & 3 & 4 & 5 \\
\hline $6 \mathrm{D}$ & 28. Tengo ganas de estar todo el día acostada(o). & 1 & 2 & 3 & 4 & 5 \\
\hline $6 \mathrm{~A}$ & 29. Al aceptar la enfermedad, siento que me quiero más. & 1 & 2 & 3 & 4 & 5 \\
\hline $7 \mathrm{~N}$ & 30. Me engaño al negar la enfermedad. & 1 & 2 & 3 & 4 & 5 \\
\hline 71 & 31. Me enojo con la vida por tener la enfermedad. & 1 & 2 & 3 & 4 & 5 \\
\hline $7 \mathrm{P}$ & 32. La fe me ayuda a pensar positivamente. & 1 & 2 & 3 & 4 & 5 \\
\hline 7D & 33. Siento que no hay nada por lo que luchar. & 1 & 2 & 3 & 4 & 5 \\
\hline $7 \mathrm{~A}$ & 34. Acepto el hecho de tener la enfermedad. & 1 & 2 & 3 & 4 & 5 \\
\hline $8 \mathrm{~N}$ & 35. Tengo miedo de hacerle frente a mi situación. & 1 & 2 & 3 & 4 & 5 \\
\hline 81 & $\begin{array}{l}\text { 36. Me enojo con conmigo misma(o) por tener la enferme- } \\
\text { dad. }\end{array}$ & 1 & 2 & 3 & 4 & 5 \\
\hline $8 \mathrm{P}$ & 37. Pienso que mi fe mejorará mi salud. & 1 & 2 & 3 & 4 & 5 \\
\hline $8 \mathrm{D}$ & 38. Tengo pensamientos negativos. & 1 & 2 & 3 & 4 & 5 \\
\hline $8 \mathrm{~A}$ & 39. Acepto con resignación la enfermedad. & 1 & 2 & 3 & 4 & 5 \\
\hline $9 \mathrm{~N}$ & 40. Suelo ignorar que tengo la enfermedad. & 1 & 2 & 3 & 4 & 5 \\
\hline 9l & 41. Siento mucho coraje por tener la enfermedad. & 1 & 2 & 3 & 4 & 5 \\
\hline 9P & 42. Pienso que mi fe me ayudará a salir adelante. & 1 & 2 & 3 & 4 & 5 \\
\hline 9D & 43. No tengo ganas de hacer nada. & 1 & 2 & 3 & 4 & 5 \\
\hline $9 \mathrm{~A}$ & 44. Tomo las cosas como son. & 1 & 2 & 3 & 4 & 5 \\
\hline $10 \mathrm{~N}$ & 45. Me resulta tan dolorosa la realidad que prefiero negarla. & 1 & 2 & 3 & 4 & 5 \\
\hline 101 & 46. Pienso por qué a mí. & 1 & 2 & 3 & 4 & 5 \\
\hline $10 P$ & $\begin{array}{l}\text { 47. Creo que el doctor me va a curar, si sigo todas sus indi- } \\
\text { caciones }\end{array}$ & 1 & 2 & 3 & 4 & 5 \\
\hline $10 \mathrm{D}$ & $\begin{array}{l}\text { 48. Pienso que la enfermedad es un castigo por algo que } \\
\text { hice. }\end{array}$ & 1 & 2 & 3 & 4 & 5 \\
\hline $10 \mathrm{~A}$ & 49. Siento que voy a superar la enfermedad. & 1 & 2 & 3 & 4 & 5 \\
\hline $11 \mathrm{~N}$ & 50. Me siento incapaz de aceptar la enfermedad. & 1 & 2 & 3 & 4 & 5 \\
\hline 111 & 51. Siento que es injusto tener la enfermedad. & 1 & 2 & 3 & 4 & 5 \\
\hline $11 P$ & $\begin{array}{l}\text { 52. Realizo promesas u ofrecimientos esperando una cura- } \\
\text { ción. }\end{array}$ & 1 & 2 & 3 & 4 & 5 \\
\hline 11D & 53. Siento que se me acaban las fuerzas. & 1 & 2 & 3 & 4 & 5 \\
\hline $11 \mathrm{~A}$ & $\begin{array}{l}\text { 54. El apoyo de mis seres queridos me ayuda a aceptar } \\
\text { la enfermedad. }\end{array}$ & 1 & 2 & 3 & 4 & 5 \\
\hline $12 \mathrm{~N}$ & $\begin{array}{l}\text { 55. Niego la enfermedad por miedo a que me tengan lásti- } \\
\text { ma. }\end{array}$ & 1 & 2 & 3 & 4 & 5 \\
\hline 121 & 56. Me enoja el no poder hacer mi vida normal. & 1 & 2 & 3 & 4 & 5 \\
\hline $12 \mathrm{P}$ & 57. Pienso que mi fe me ayudará a tener un mejor futuro. & 1 & 2 & 3 & 4 & 5 \\
\hline $12 \mathrm{D}$ & $\begin{array}{l}\text { 58. He perdido el interés en casi todas las actividades de } \\
\text { mi vida. }\end{array}$ & 1 & 2 & 3 & 4 & 5 \\
\hline $12 \mathrm{~A}$ & $\begin{array}{l}\text { 59. Pienso que hay algo bueno que aprender de la enfer- } \\
\text { medad. }\end{array}$ & 1 & 2 & 3 & 4 & 5 \\
\hline
\end{tabular}




\begin{tabular}{|c|l|c|c|c|c|c|}
\hline F.E. & \multicolumn{1}{|c|}{ Ítem } & \multicolumn{4}{|c|}{ Frecuencia } \\
\hline $13 \mathrm{~N}$ & 60. Me siento mejor al negar la enfermedad. & 1 & 2 & 3 & 4 & 5 \\
\hline $13 \mathrm{~A}$ & 61. Aceptar la enfermedad, me hace sentir más tranquila(o). & 1 & 2 & 3 & 4 & 5 \\
\hline $14 \mathrm{~N}$ & 62. No quiero enterarme de lo que me sucede. & 1 & 2 & 3 & 4 & 5 \\
\hline $14 \mathrm{~A}$ & 63. Pienso que voy a salir pronto de esto. & 1 & 2 & 3 & 4 & 5 \\
\hline $15 \mathrm{~N}$ & 64. No puedo creer que tenga esta enfermedad. & 1 & 2 & 3 & 4 & 5 \\
\hline $15 \mathrm{~A}$ & 65. Aceptar la enfermedad, me brinda bienestar. & 1 & 2 & 3 & 4 & 5 \\
\hline $16 \mathrm{~N}$ & $\begin{array}{l}\text { 66. Necesito la opinión de otros doctores porque no creo en } \\
\text { el diagnóstico. }\end{array}$ & 1 & 2 & 3 & 4 & 5 \\
\hline
\end{tabular}

F.E: Factor esperado: N = Negación, I = Ira, P = Pacto, D = Depresión y A = Aceptación. 